\title{
PERANCANGAN ULANG EXTRUSION TORQUE UNTUK INSTALASI PANEL KACA DENGAN PENDEKATAN ERGONOMI
}

\author{
Silvi Ariyanti dan Kiki Arifin \\ Program Studi Teknik Industri Universitas Mercu Buana \\ e-mail: ariyantisilvi41@gmail.com
}

\begin{abstract}
ABSTRAK
Pekerjaan konstruksi memiliki resiko yang tinggi, salah satu jenis bahaya yang terdapat dikonstruksi ini yaitu bahaya ergonomi. Bahaya ergonomi yang sering terjadi adalah pada saat installasi material. Pemasangan bracket lantai pada instalasi kaca memiliki resiko yang cukup berbahaya untuk kesehatan sehingga mendapatkan perhatian khusus. Disamping ketidakwajaran postur yang dimiliki oleh pekerja, pekerjaan tersebut memerlukan waktu sekitar 20-30 menit untuk satu kali pemasangan. Adapun tujuan dari penelitian ini adalah: Rancang ulang extrusion torque untuk intalasi panel kaca dan membandingkan resiko kerja sebelum dan sesudah adanya alat bantu kerja tersebut. Metode penelitian yang digunakan adalah kusioner Nordic Body Map (NBM), Rapid Entire Body Assessment, Anthopometri dan proses perancangang produk. Setelah dihasilkan rancang bangun alat bantu extrusion torque dapat mengurangi resiko ergonomi terjadi pengurangan pada keluhan fisik dari pekerja. Berdasarkan perbandingan analisa REBA pada postur tubuh pekerja sebelum menggunakan extrusion torque yang baru berada pada skor 9 dan setelah menggunakan extrusion torque yang baru diperoleh nilai REBA 6. Pada saat dilakukan wawancara dengan menggunakan kuisioner NBM, ditemukan bahwa pekerja mengalami keluhan-keluhan fisik yang terjadi pada bagian tubuh terdiri dari 12 titik keluhan fisik dan setelah implementasi terjadi pengurangan jumlah keluhan menjadi 4 keluhan.
\end{abstract}

Kata kunci: Extrusion Torque, Ergonomi, REBA, Nordic Body Map.

ABSTRACT

Construction work has a high risk, one of the types of hazards found in this construction is ergonomic hazards. Ergonomic hazards that often occur are during material installation. Installation of floor brackets in glass installations has a risk that is quite dangerous for health, so get special attention. In addition to the irregularity of the posture that is owned by the worker, the job takes around 20-30 minutes for one installation. The objectives of this study are: Redesign of extrusion torque for glass panel installation and compare the work risk before and after the existence of the work aid. The research method used is questionnaire Nordic Body Map (NBM), Rapid Entire Body Assessment, Anthopometry and product design process. After the design of the extrusion torque generated can reduce the risk of ergonomics a reduction in physical complaints from workers. Based on the comparison of REBA analysis on workers' body posture before using the new extrusion torque at a score of 9 and after using extrusion torque the newly obtained REBA value 6. At the time of the interview using the NBM questionnaire, it was found that workers experienced physical complaints that occurred at body parts consist of 12 physical complaints points and after implementation there is a reduction in the number of complaints to 4 complaints.

Keywords: Extrusion Torque, Ergonomics, REBA, Nordic Body Map.

\section{PENDAHULUAN}

Manusia merupakan faktor terpenting dalam sistem kerja. Manusia mampu melaksanakan kegiatannya dengan maksimal karena kondisi fisik yang baik [1]. Namun dalam kenyataanya banyak perusahaan yang kurang memperhatikan kondisi fisik yang baik pada saat merancang sistem kerjanya, serta masih kurang memperhatikan prinsip-prinsip ergonomi yang menyebabkan para pekerja tidak dapat bekerja secara optimal. Berdasarkan hasil survey departemen kesehatan menunjukkan bahwa sekitar 40,5\% penyakit yang diderita pekerja berhubungan dengan pekerjaanya, gangguan kesehatan yang dialami pekerja terutama untuk pekerja konstruksi, umumnya berupa gangguan muskuloskeletal. Bahaya ergonomi yang sering terjadi adalah pada saat instalasi material. Pekerja merasa 
cukup lelah dan tidak nyaman sehingga dapat mengakibatkan terjadinya cidera dan lebih dari $25 \%$ dari total kecelakaan kerja terjadi berkaitan dengan pekerjaan instalasi material. Dikarenakan bekerja dalam postur janggal seperti membungkuk, jongkok dan memiringkan badan. Faktor-faktor inilah yang berpengaruh dengan musculoskeletal ligamen, sendi, tulang rawan, pembuluh darah, dan cakram tulang belakang.

Suma'mur tahun 1989 menjelaskan, bahwa keluhan-keluhan pada tulang belakang yang dialami pekerja jika terus dibiarkan berpeluang besar menyebabkan dislokasi bagian tulang punggung yang menimbulkan rasa sangat nyeri dan bisa irreversible serta fatal. Pada pekerjaan mengangkat dan mengangkut, efisiensi kerja dan pencegahan kerusakan tulang belakang harus mendapat perhatian yang cukup [2].

Musculosceletal Disorders (MSDs) terjadi akibat dari pekerjaan yang tidak sesuai dengan kapasitas fisik pekerja sehingga pada akhirnya menyebabkan kerusakan pada tubuh pekerja khususnya kerusakan pada sistem otot dan tulang [3]. Seperti yang ditunjukkan pada Gambar 1 yang merupakan ilustrasi proses pemasangan bracket lantai.

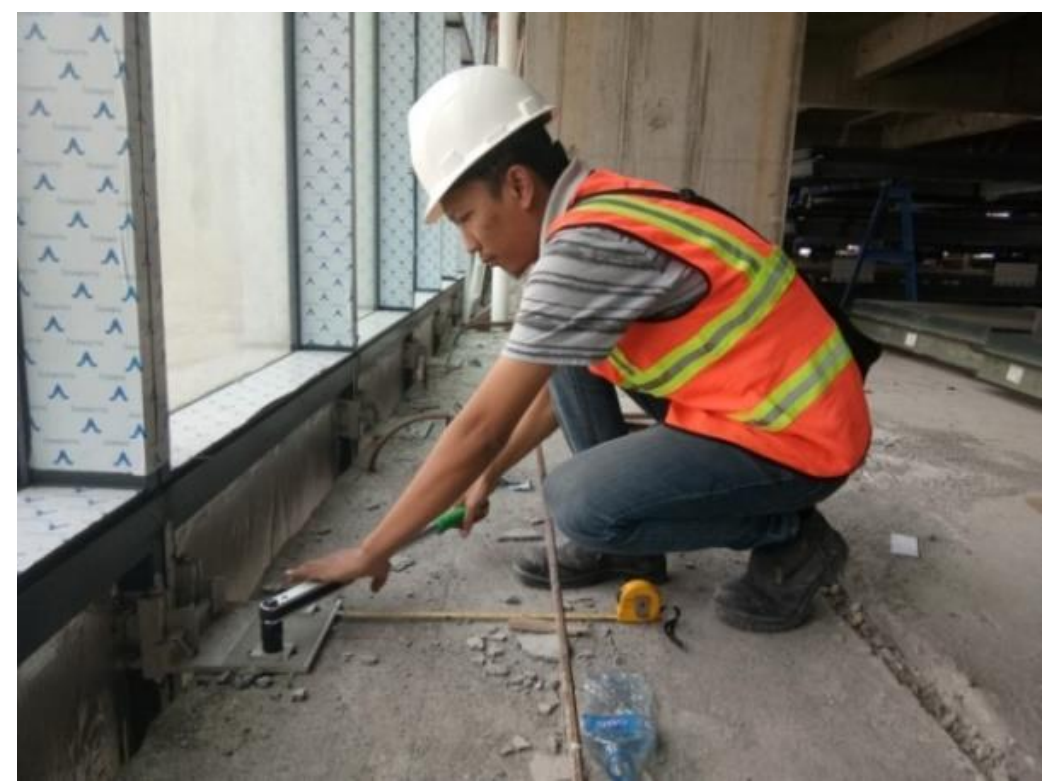

Gambar 1. Postur Pekerja pada Pemasangan Braket Lantai

Berdasarkan Gambar 1 dapat dilihat bahwa postur proses pemasangan bracket lantai dengan menggunakan extrusion torque yang ada saat ini tentunya memiliki resiko yang cukup berbahaya. Disamping ketidakwajaran postur yang dimiliki oleh pekerja, pekerjaan tersebut memerlukan waktu sekitar 20-30 menit untuk menyelesaikan pekerja memasangan bracket lantai tersebut.

Berdasarkan latar belakang diatas maka tujuan penelitian yang dilakukan adalah: rancang ulang extrusion torque pada intalasi kaca dan membandingkan resiko kerja sebelum dan sesudah adanya alat bantu kerja yang baru.

NBM merupakan salah satu metode pengukuran subjektif untuk mengukur rasa sakit otot para pekerja. Penilaian subjektif tentang keparahan pada sistem musculoskeletal dapat dilakukan dengan metode NBM. NBM adalah salah satu cara evaluasi ergonomik terhadap keluhan musculoskeletal [4]. Keluhan subjektif ini dipilih karena berdasarkan penelitian oleh The National Institute for Occupational Safety and Health (1997) yang menyatakan bahwa keluhan subjektif menjadi pilihan yang baik untuk melihat keluhan Work-related Muskuloskeletal Disorder [5]. Dalam NBM terdapat bagian tubuh utama yaitu: leher, siku, bahu, pinggang, punggung bagian atas, lutut, pergelangan tangan/tangan, tumit/kaki, dan punggung bagian bawah. 


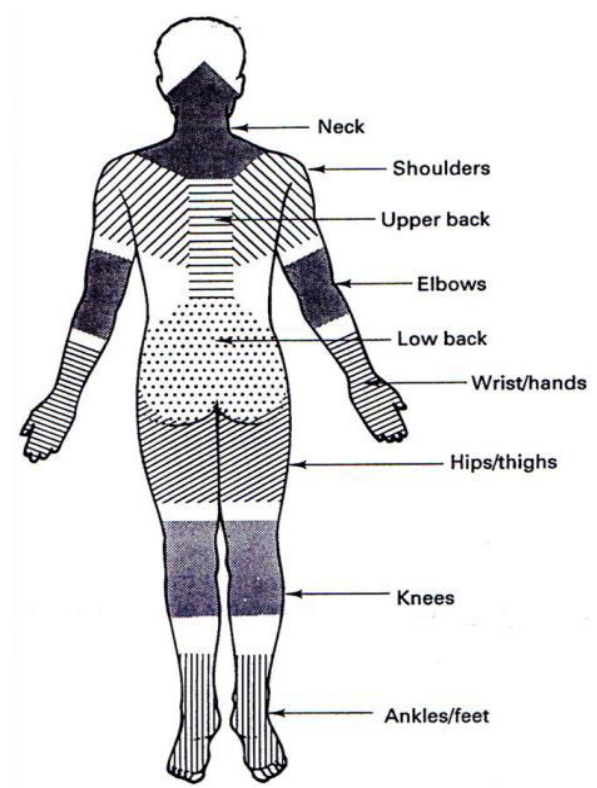

Gambar 2. Bagian Tubuh Utama

Kuesioner NMB memiliki 28 titik atau pertanyaan dimulai dari 0 hingga 27 titik nomor yang dinilai dengan menggunakan skala likert untuk melihat tingkatan keluhan MSDs secara objektif. Semua dikelompokkan menjadi tiga bagian, yaitu Leher, upper limb (bahu, siku, tangan, dan pergelangan tangan), lower limb (pinggul, paha, lutut, pergelangan kaki, dan kaki) dan low back (punggung atas dan bawah). MSDs merupakan sekumpulan gejala/gangguan yang berkaitan dengan jaringan otot, tendon, ligamen, kartilago, sistem saraf, struktur tulang, dan pembuluh darah. MSDs pada awalnya menyebabkan sakit, nyeri, mati rasa, kesemutan, bengkak, kekakuan, gemetar, gangguan tidur, dan rasa terbakar [3]. MSDs adalah kelainan yang disebabkan penumpukan cidera atau kerusakan-kerusakan kecil pada sistem muskuloskeletal akibat trauma berulang yang setiap kalinya tidak bisa sembuh secara sempurna, sehingga membentuk kerusakan cukup besar untuk menimbulkan rasa sakit [6]. Keluhan hingga kerusakan inilah yang biasanya diistilahkan dengan keluhan Musculoskeletal Disorders (MSDs) atau cidera pada sistem muskuloskeletal [7][8].

Kelelahan diklasifikasikan dalam dua jenis, yaitu kelelahan otot dan kelelahan umum. Kelelahan otot adalah merupakan tremor pada otot/perasaan nyeri pada otot. Sedang kelelahan umum biasanya ditandai dengan berkurangnya kemauan untuk bekerja yang disebabkan oleh karena monotoni, intensitas dan lamanya kerja fisik, keadaan lingkungan, sebab-sebab mental, status kesehatan dan keadaan gizi [7].

Sikap kerja yang sering dilakukan oleh manusia dalam melakukan pekerjaan antara lain berdiri, duduk, membungkuk, jongkok, berjalan, dan lain-lain. Sikap kerja tersebut dilakukan tergantung dari kondisi dari sistem kerja yang ada. Jika kondisi sistem kerjanya yang tidak sehat akan menyebabkan kecelakaan kerja, karena pekerja melakukan pekerjaan yang tidak aman. Menurut Bridger (1995) sikap kerja yang salah, canggung, dan di luar kebiasaan akan menambah resiko cidera pada bagian sistem musculoskeletal [9].

Data antropometri sangat penting dalam menentukan alat dan cara mengoperasikanya. Kesesuaian hubungan antara antropometri pekerja dengan alat yang digunakan sangat berpengaruh pada sikap kerja, tingkat kelelahan, kemampuan kerja dan produktivitas kerja. Antropometri juga menentukan dalam seleksi penerimaan tenaga kerja tinggi, pekerjaan yang memerlukan kelincahan, dll. Data antropometri dapat digunakan untuk mendesain pakaian, tempat kerja, lingkungan kerja, mesin, alat dan sarana kerja serta produk-produk untuk konsumen [10]. 


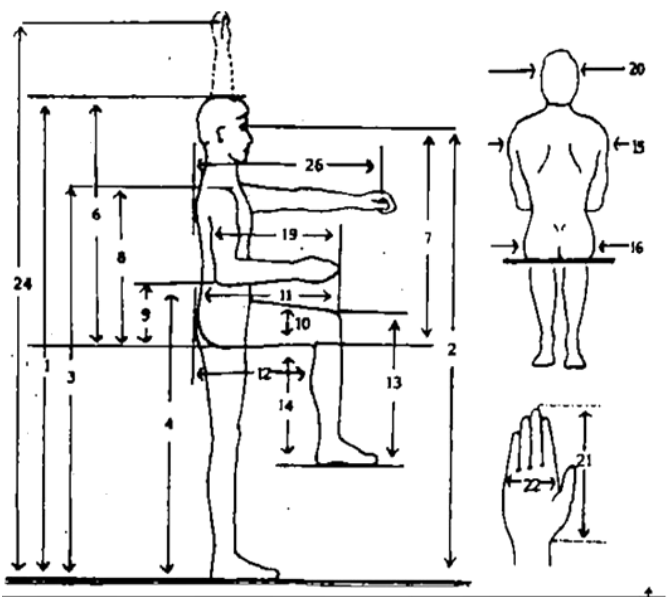

Gambar 3. Antropometri Tubuh manusia yang Diukur Dimensinya [11]

Rapid Entire Body Assessment (REBA) merupakan salah satu metode yang digunakan dalam menganalisis pekerjaan berdasarkan postur tubuh pekerja. Evaluasi Menggunakan Rapid Entire Body Assessment (REBA) worksheet dilakukan dengan memberikan skor pada bagian tubuh tertentu yaitu pergelangan tangan, lengan bagian bawah, siku, bahu, leher, bagian depan tubuh, punggung, kaki dan lutut. Setelah semua data didaptkan, akan ditemukan variabel faktor resiko yang mempresentasikan level resiko pada MSD.

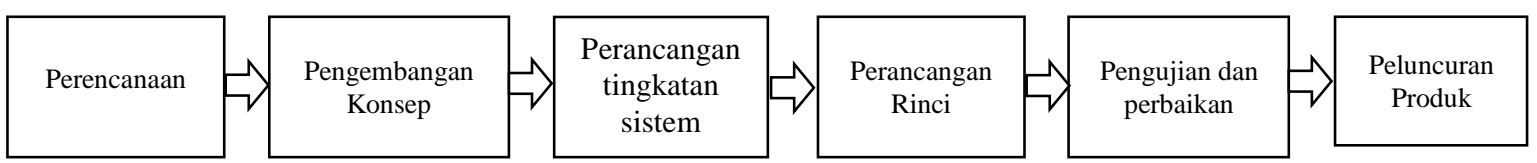

Gambar 4. Fase Perancangan

Proses perancangan dan pengembangan produk menurut Darian dan Eppinger tahun 2011 terdiri atas 6 fase seperti yang ditunjukkan pada Gambar 4 yaitu: perencanaan, Pengembangan konsep, Perancangan tingkatan sistem, Perancangan rinci, pengujian dan perbaikan dan peluncuran Produk.

\section{METODE PENELITIAN}

Langkah-langkah penelitian yang dilakukan dapat dilihat pada pada Gambar 4.
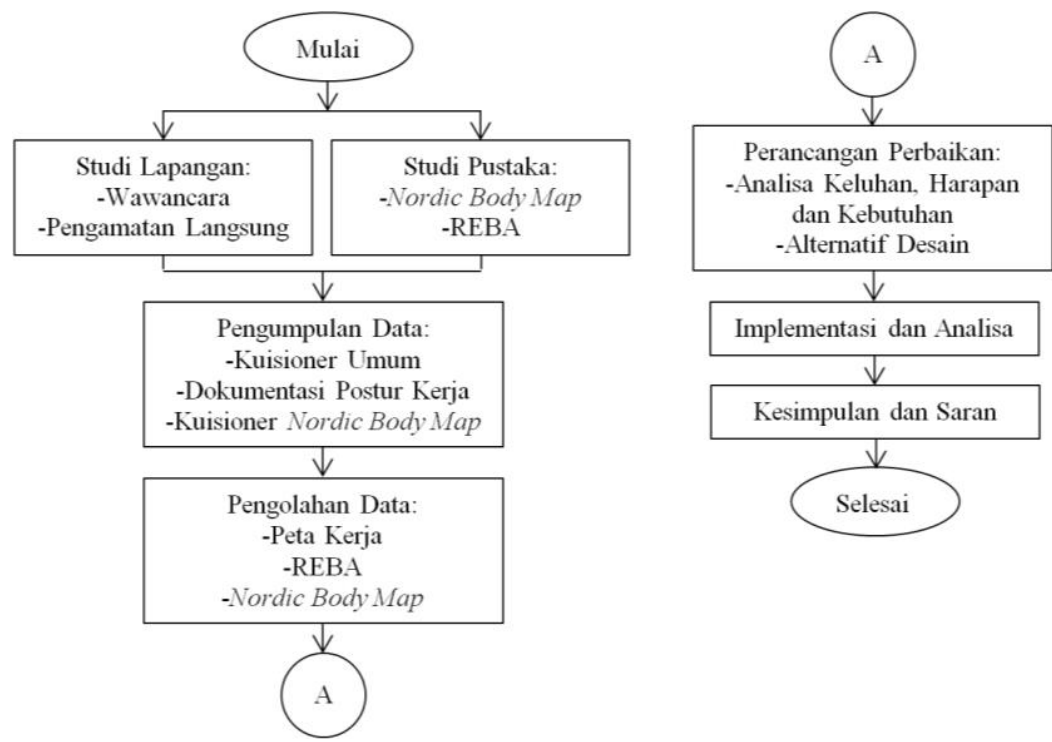

Gambar 5. Flowchart Penelitian 
Dalam penelitian ini data yang digunakan adalah kusioner NBM dan foto aktivitas instalasi kaca. Setelah analisa data dilakukan tahap merancang yang ingin dibuat untuk mengurangi keluhan, postur yang buruk, maupun tingkat berat pekerjaan yang dilakukan, proses merancang alat bantu juga mempertimbangkan keluhan, harapan dan kebutuhan pekerja lalu dari beberapa konsep yang ada maka akan dilakukan seleksi menggunakan pengamatan dengan deskripsi konsep alat agar didapatkan satu rancangan yang terbaik sehingga alat yang diciptakan dapat benar-benar membantu pekerja.

\section{HASIL DAN PEMBAHASAN \\ Analisa Pekerjaan Sebelum adanya Extrusion Torque yang Baru}

\begin{tabular}{|c|c|c|c|c|c|}
\hline No & Aktifitas & Gambar Postur & $\begin{array}{c}\text { Skor } \\
\text { REBA }\end{array}$ & $\begin{array}{c}\text { Level } \\
\text { Resiko } \\
\end{array}$ & $\begin{array}{c}\text { Hasil } \\
\text { Analisis } \\
\end{array}$ \\
\hline 1. & $\begin{array}{c}\text { Pemasangan } \\
\text { Bracket }\end{array}$ & & 9 & Tinggi & $\begin{array}{c}\text { Diperlukan } \\
\text { tindakan } \\
\text { secepatnya untuk } \\
\text { perbaikan dan } \\
\text { implementasi } \\
\text { perubahan }\end{array}$ \\
\hline
\end{tabular}

Dari pengumpulan dan pengolahan data kuisioner NBM dapat ditemukan keluhan fisik yang dialami ketika melakukan pekerjaan saat ini keluhan fisik yang paling utama yaitu pada bagian bahu, punggung, pinggang, tangan kanan, lutut, paha dan betis.

Berikut penjabaran keluhan, harapan dan serta kebutuhan desain alat bantu dapat dilihat pada Tabel 2.

Tabel 2. Analisa Keluhan, Harapan, Kebutuhan dan Desain Alat

\begin{tabular}{|c|c|c|c|c|}
\hline No. & Keluhan & Harapan & Kebutuhan & Desain Alat \\
\hline 1. & $\begin{array}{l}\text { Adanya rasa nyeri otot } \\
\text { pada bagian bahu dan } \\
\text { punggung }\end{array}$ & $\begin{array}{l}\text { Pekerja tidak harus } \\
\text { melakukan dalam postur } \\
\text { tubuh yang menunduk } \\
\text { dan bahu yang tertekuk } \\
\text { dalam jangka waktu } \\
\text { berulang-ulang }\end{array}$ & $\begin{array}{l}\text { Alat bantu lebih tinggi } \\
\text { yang dapat memperbaiki } \\
\text { postur tubuh pekerja } \\
\text { keluhan nyeri pada otot }\end{array}$ & $\begin{array}{l}\text { Desain alat bantu } \\
\text { disesuaikan dengan } \\
\text { antropometri pekerja dan } \\
\text { disesuaikan posisi } \\
\text { kerjanya agar nyaman dan } \\
\text { mengurangi resiko nyeri } \\
\text { pada otot }\end{array}$ \\
\hline 2. & $\begin{array}{l}\text { Adanya rasa nyeri pada } \\
\text { bagian tangan kanan } \\
\text { dan lengan atas kanan }\end{array}$ & $\begin{array}{l}\text { Adanya alat untuk } \\
\text { membantu menjadi lebih } \\
\text { seimbang dalam } \\
\text { pengencangan bracket } \\
\text { dan dapat mengurangi } \\
\text { resiko cedera pada tangan } \\
\text { kanan }\end{array}$ & $\begin{array}{l}\text { Membuat alat bantu } \\
\text { pengencangan bracket } \\
\text { yang mengurangi resiko } \\
\text { cedera }\end{array}$ & $\begin{array}{l}\text { Desain alat bantu yang } \\
\text { dapat mengurangi resiko } \\
\text { cidera dan rasa nyeri agar } \\
\text { pekerja lebih nyaman dan } \\
\text { safety dalam bekerja. }\end{array}$ \\
\hline 3. & $\begin{array}{l}\text { Adanya rasa nyeri pada } \\
\text { bagian paha, Lutut, dan } \\
\text { Betis akibat postur } \\
\text { tubuh pekerja yang } \\
\text { jongkok }\end{array}$ & $\begin{array}{l}\text { Adanya alat bantu untuk } \\
\text { menopang untuk lebih } \\
\text { tinggi sehingga postur } \\
\text { tubuh pekerja tidak dalam } \\
\text { keadaan jongkok }\end{array}$ & $\begin{array}{l}\text { Adanya extrusion yang } \\
\text { dapat membantu sehingga } \\
\text { pekerja tidak harus } \\
\text { bekerja dalam keadaan } \\
\text { jongkok }\end{array}$ & $\begin{array}{l}\text { Desain alat bantu } \\
\text { disesuaikan dengan } \\
\text { antropometri pekerja agar } \\
\text { lebih nyaman dan keluhan } \\
\text { dapat berkurang }\end{array}$ \\
\hline 4. & $\begin{array}{l}\text { Proses pengencangan } \\
\text { bracket yang berulang } \\
\text { sehingga menimbulkan } \\
\text { cidera otot }\end{array}$ & $\begin{array}{l}\text { Pekerja tidak harus } \\
\text { jongkok dalam } \\
\text { mengencangkan bracket }\end{array}$ & $\begin{array}{l}\text { Alat bantu yang dapat } \\
\text { mengurangi keluhan } \\
\text { cidera pada otot }\end{array}$ & $\begin{array}{l}\text { Desain alat bantu agar } \\
\text { dapat membantu pekerja } \\
\text { dan mengurangi resiko } \\
\text { cidera otot }\end{array}$ \\
\hline
\end{tabular}

\section{Alternatif Desain}

Tahap ini bertujuan untuk mengumpulkan alternatif desain extrusion torque yang dapat digunakan dan sesuai untuk menyelesaikan masalah keluhan-keluhan fisik yang 
dialami oleh pekerja. Alternatif-alternatif tersebut kemudian diklasifikasikan dan dijelaskan dengan langkah-langkah penggunaan untuk menentukan desain alat bantu seperti yang ditunjukkan pada Tabel adalah sebagai berikut: menentukan Karakteristik yang penting untuk rancangan yang terdiri dari material dan ukuran.

Tabel 3. Karakteristik dan Alternatif Desain

\begin{tabular}{ccc}
\hline Karakteristik & Alternatif Desain & Description \\
\hline & & Sangat kuat \\
& Carbon steel & Tahan Lama \\
Material & & Memiliki Stiffnes tinggi \\
& & Tidak mudah Melendut \\
& Kekuatan lebih rendah \\
& Alumunium & Lebih Ringan \\
& & Lebih mudah patah \\
& & Mudah melendut \\
& & Lebih Panjang \\
Panjang/ukuran & 500 & Tahan lama \\
(mm) & & Memiliki Stiffnes tinggi \\
& & posisi pekerja lebih ideal \\
& & Lebih Pendek \\
& & Tahan Lama \\
& & posisi pekerja kurang ideal
\end{tabular}

Berikut ini adalah desain alat bantu dari alternatif 1 material carbon steel dengan panjang $500 \mathrm{~mm}$ yang dapat dilihat pada Gambar 6 .

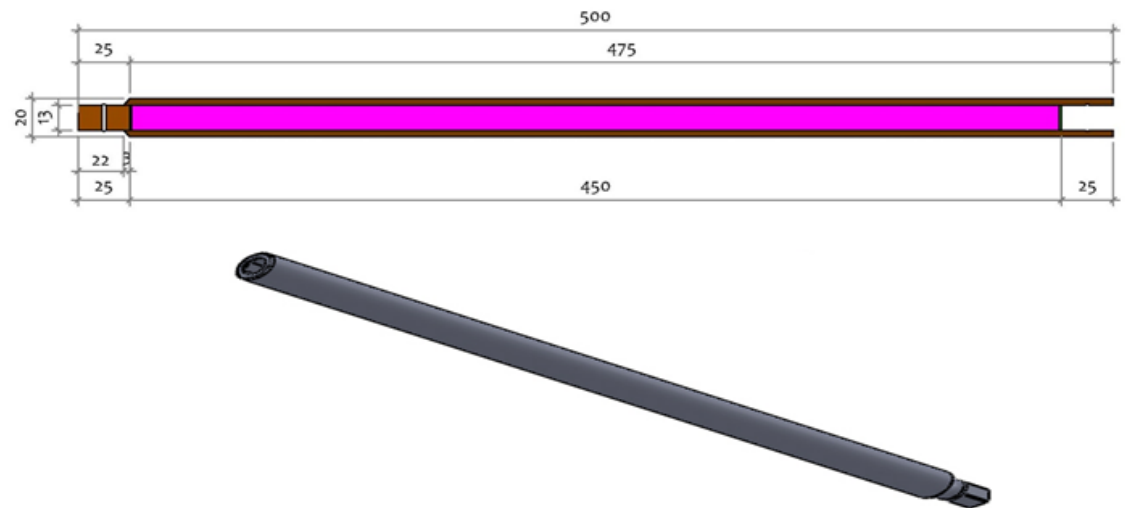

Gambar 6. Alternatif 1 Alat Bantu Instalasi Kaca

Berikut ini adalah desain alat bantu dari alternatif 2 dengan material aluminium yang dapat dilihat pada Gambar 7.

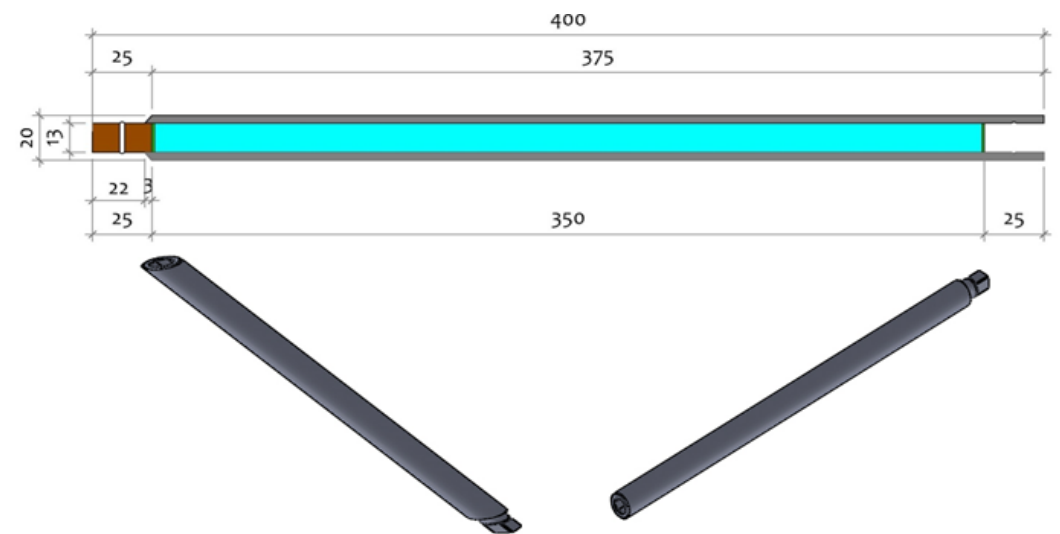

Gambar 7. Alternatif 2 Alat Bantu Instalasi Kaca 
Berikut ini adalah alat torsi yang digunakan \& aplikasi dilapangan dilihat pada Gambar 9. Dari kedua alternatif disain diatas maka yang terpilih adalah alternatif 1 dengan pertimbangan sangat kuat, tahan lama, memiliki stiffnes tinggi, tidak mudah melendut, lebih panjang dan posisi kerja lebih ideal.
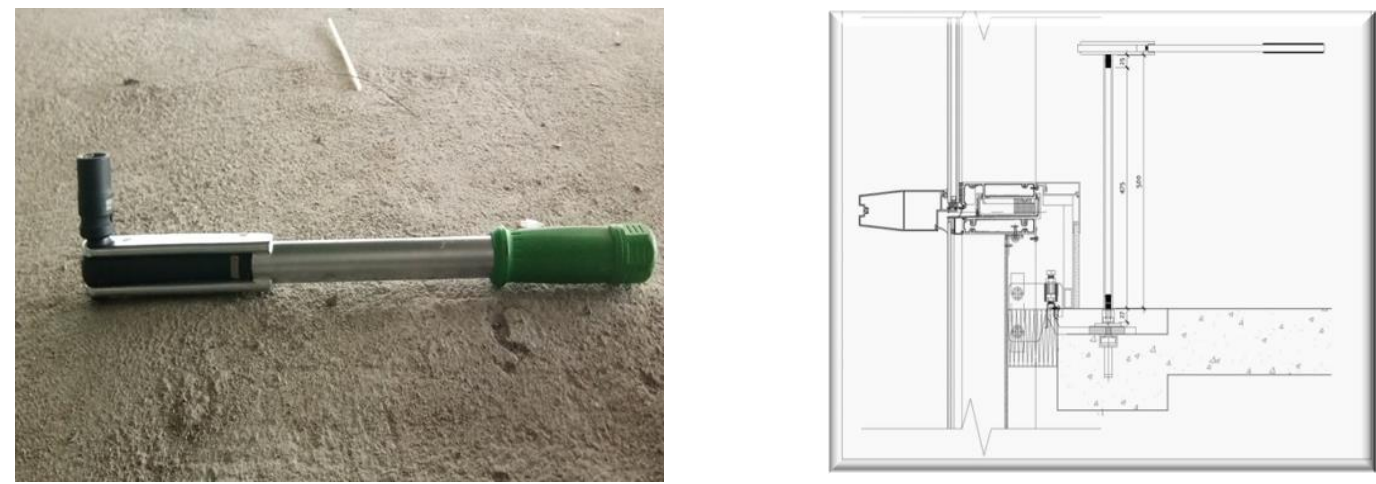

Gambar 8. Alat Torsi \& Aplikasi dilapangan

\section{Analisa Setelah Implementasi}

Tabel 4. Hasil REBA Untuk Gambar Postur

\begin{tabular}{ccccc}
\hline Aktifitas & Skor REBA & Level Resiko & Hasil Analisis \\
\hline $\begin{array}{c}\text { Pemasangan Bracket } \\
\text { Responden 1 }\end{array}$ & & & Sedang & $\begin{array}{c}\text { Perlu adanya } \\
\text { Tindakan lanjutan } \\
\text { dan implementasi } \\
\text { perubahan }\end{array}$ \\
\end{tabular}

Setelah dilakukan implementasi maka dilakukan pengukuran ulang postur pekerja untuk mengetahui perubahan yang terjadi. Berikut merupakan gambar postur pekerja sesudah implementasi.

Dari pengumpulan dan pengolahan data kuisioner $N B M$ dapat ditemukan keluhan fisik yang dialami ketika melakukan pekerjaan saat ini. keluhan fisik yang paling utama yaitu pada bagian punggung, lutut, betis dan pergelangan kaki.

Tabel 5. Analisa Keluhan Fisik dan Penyebabnya

\begin{tabular}{|c|c|c|}
\hline No & Urutan Keluhan Fisik & Analisa Penyebab Keluhan \\
\hline 1. & Sakit Punggung & $\begin{array}{l}\text { Pekerja mengalami sakit punggung karena pada saat pengencangan } \\
\text { bracket posisi pekerja menunduk yang membuat punggung terasa } \\
\text { lebih cepat lelah. }\end{array}$ \\
\hline 2. & Sakit Lutut Kanan & $\begin{array}{l}\text { Pada saat proses pengencangan bracket pekerja harus dengan posisi } \\
\text { agak menekuk, dibuktikan oleh postur REBA yang kurang baik. }\end{array}$ \\
\hline 3. & Sakit Betis kanan & $\begin{array}{l}\text { Pada saat proses pengencangan bracket pekerja harus dengan agak } \\
\text { menekuk untuk bagian kaki, dibuktikan oleh postur REBA yang } \\
\text { buruk. }\end{array}$ \\
\hline 4. & $\begin{array}{l}\text { Sakit Pergelangan kaki } \\
\text { kanan }\end{array}$ & $\begin{array}{l}\text { Pada saat mengencangkan bracket kamungkinan kaki pada bagian } \\
\text { kanan menahan beban untuk pengencangan, dibuktikan oleh postur } \\
\text { tubuh REBA. }\end{array}$ \\
\hline
\end{tabular}


Perancangan Ulang Extrusion Torque untuk Instalasi Panel Kaca dengan Pendekatan Ergonomi Silvi Ariyanti dan Kiki Arifin

Tabel 6. Perbandingan REBA Sebelum \& setelah Implementasi

\begin{tabular}{cccccc}
\hline \multicolumn{2}{c}{ Sebelum Implementasi } & \multicolumn{4}{c}{ Setelah Implementasi } \\
\hline Aktifitas & $\begin{array}{c}\text { Skor } \\
\text { REBA }\end{array}$ & $\begin{array}{c}\text { Level } \\
\text { Resiko }\end{array}$ & Aktifitas & $\begin{array}{c}\text { Skor } \\
\text { REBA }\end{array}$ & $\begin{array}{c}\text { Level } \\
\text { Resiko }\end{array}$ \\
\hline $\begin{array}{c}\text { Pemasangan Bracket } \\
\text { Sebelum Implementasi }\end{array}$ & 9 & Tinggi & $\begin{array}{c}\text { Pemasangan Bracket } \\
\text { Rersponden 1 Setelah } \\
\text { Implementasi }\end{array}$ & 6 & Sedang \\
\hline
\end{tabular}

Tabel menunjukkan bahwa pemasangan instalasi kaca dengan alat bantu kerja yang baru dapat mengurangi resiko kerja.

\section{KESIMPULAN}

Setelah dihasilkan rancang bangun alat bantu extrusion torque dapat mengurangi resiko ergonomi terjadi pengurangan pada keluhan fisik dari pekerja. Berdasarkan perbandingan analisa REBA pada postur tubuh pekerja sebelum menggunakan extrusion torque yang baru berada pada skor 9 dan setelah menggunakan extrusion torque yang baru diperoleh nilai REBA 6. Pada saat dilakukan wawancara dengan menggunakan kuisioner.

NBM, ditemukan bahwa pekerja mengalami keluhan-keluhan fisik yang terjadi pada bagian tubuh terdiri dari 12 titik keluhan fisik dan setelah implementasi terjadi pengurangan jumlah keluhan menjadi 4 keluhan. Hal ini menunjukkan bahwa extrusion torque yang baru lebih baik secara ergonomik dari pada alat extrusion torque sebelumnya.

\section{DAFTAR PUSTAKA}

[1]. Rochman, Taufiq., Rahmaniyah D.A., \& Miftahudin. 2012. Usulan Perbaikan Terhadap Aktivitas Penurunan Pasir Di Depo Pasir Makmur Menggunakan Pendekatan Postur Kerja Dan Assessment Terhadap Fisiologi Kerja. ISSN:1979911X. Surakarta : Universitas Sebelas Maret.

[2]. Suma'mur P.K. 1989. Ergonomi untuk Produktivitas Kerja. Jakarta: CV Haji Mas Agung.

[3]. OSHA, 2000. Ergonomics: The Studi of Works. U.S. Department of Labour.

[4]. Nurliah, A. 2012. Analisis Resiko Musculoskeletal Disorder (MSDs) pada Operator Forklift di PT. LLI. Depok.

[5]. NIOSH, 1997. Musculoskeletal Disorders and Workplace Factors: A Critical Review of Epidemiologic Evidence for Work Related Musculoskeletal Disorders. NIOSH: Centers for Disease Control and Prevention.

[6]. Humantech, 1995. Applied Ergonomics Trainning Manual Second Edition. Australia: Barkeley Vale.

[7]. Grandjean, E 1993. Fitting The Task to The Man, fourth Edistio. London: Taylor and Francis Inc.

[8]. Tarwaka. 2004. Ergonomi untuk Kesehatan, Keselamatan dan Produktivitas. Edisi I, Cetakan I. Surakarta: UNIBA Press.

[9]. Bridger, R.S. 1995. Introduction to Ergonomics, International Editions. Singapore: McGraw-Hill Book Co.

[10]. Pulat, B.M.1992. Fundamental of Industrial Ergonomics. USA: Hall International Englewood Clifts, New Jersey.

[11]. Nurmianto, Eko. 2004. Ergonomi Konsep Dasar dan Aplikasinya: Tinjauan, Anantomi, Fisiologi, Antropometri, Psikologi dan Komputasi Untuk Perancangan Kerja dan Produk. Surabaya: Penerbit Guna Widya. 